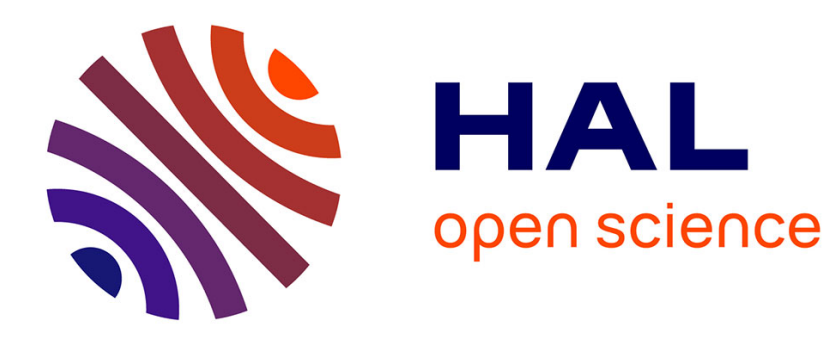

\title{
Use of kraft lignin as filler for starch films
}

Stéphanie S. Baumberger, Catherine Lapierre, Bernard B. Monties, Guy Della Valle

\section{To cite this version:}

Stéphanie S. Baumberger, Catherine Lapierre, Bernard B. Monties, Guy Della Valle. Use of kraft lignin as filler for starch films. Polymer Degradation and Stability, 1998, 59, pp.273-277. hal-02692701

\section{HAL Id: hal-02692701 https://hal.inrae.fr/hal-02692701}

Submitted on 1 Jun 2020

HAL is a multi-disciplinary open access archive for the deposit and dissemination of scientific research documents, whether they are published or not. The documents may come from teaching and research institutions in France or abroad, or from public or private research centers.
L'archive ouverte pluridisciplinaire HAL, est destinée au dépôt et à la diffusion de documents scientifiques de niveau recherche, publiés ou non, émanant des établissements d'enseignement et de recherche français ou étrangers, des laboratoires publics ou privés. 


\title{
Use of kraft lignin as filler for starch films
}

\author{
S. Baumberger, ${ }^{a *}$ C. Lapierre, ${ }^{a}$ B. Monties ${ }^{a}$ \& G. Della Valle ${ }^{b}$ \\ ${ }^{a}$ Laboratoire de Chimie Biologique, INRA, Institut National Agronomique Paris-Grignon, 78850 Thiverval Grignon, France \\ ${ }^{b}$ Laboratoire de Biochimie et Technologie des Glucides, INRA, BP 1627, 44316 Nantes Cedex 03, France
}

(Accepted 3 July 1997)

\begin{abstract}
Films containing $0-30 \%$ of commercial kraft lignin mixed with wheat starch were obtained by extrusion followed by thermal moulding. The influence of lignin content on the film mechanical properties was evaluated by stress-strain tests run at two ambient relative humidity levels. At $58 \%$ relative humidity and up to $20 \%$ lignin, a very slight increase of elongation and stress at break was observed. At $71 \%$ relative humidity and up to $30 \%$ lignin, the film resistance to elongation significantly decreased, compared to the control starch film. Dissolution tests and water sorption isotherms showed that lignin actually reduces the overall water affinity of the films. These results are consistent with the hypothesis of a twophase material consisting of a hydrophilic starch matrix filled with hydrophobic lignin aggregates, as confirmed by microscopic observations. Casting experiments showed that the lower molecular weight fraction of kraft lignin may be responsible for a slight plastification of starch. (C) 1998 Elsevier Science Limited. All rights reserved
\end{abstract}

\section{INTRODUCTION}

Among biopolymers available from agricultural resources, the potential of starch to give thermoplastics has been demonstrated, either by casting or by thermal moulding. ${ }^{1}$ The industrial development of such starchy materials as food packaging is hindered by their swelling and partial dissolution in moist environments. Chemical modification of starch has proved to be an effective way to reduce its water affinity but to the detriment of cost and biodegradability. ${ }^{2}$ Another approach is to blend starch with hydrophobic compounds.

Technical lignins available as by-products from the pulp and paper industry have already been incorporated into synthetic thermoplastics, either in their native state $^{3}$ or after grafting with compatibilizing molecules. ${ }^{4} \mathrm{~A}$ few studies also reported the properties of lignin based materials including cellulose $^{5}$ or chitosans. ${ }^{6}$

In order to study the behaviour of starch-lignin systems, we previously obtained homogeneous starch-lignosulfonates blends in the presence of a plasticizer, either by thermal moulding or by casting. ${ }^{7}$ Lignosulfonates are structurally typified

*To whom correspondence should be addressed. Fax: +33-130-81-53-73; e-mail: baumberg@cardere.grignon.inra.fr by the occurrence of highly polar sulfonic groups, which confer them water solubility and tensioactive properties. In contrast, lignins obtained from the alkaline kraft pulping process (kraft lignins) are relatively hydrophobic and poorly soluble in water at acid or neutral $\mathrm{pH}$. They are heterogeneous polymers consisting of highly cross-linked aromatic skeletons carrying some key functional groups. $^{8}$

In this paper, we preliminarily report the influence of kraft lignin on some properties of thermally moulded starchy films. As this influence may be dependent on the highly heterogeneous lignin structure, we produced cast films based on different lignin fractions prepared from commercial kraft lignin. Hypotheses concerning the molecular interactions between starch and lignin are proposed.

\section{MATERIALS AND METHODS}

\subsection{Components}

Wheat starch (type A, 87.5\% dry wt, 27\% amylose, $73 \%$ amylopectin) was commercially available (F33-Amylum Aquitaine, France). Pine kraft lignin available as Indulin AT from WESTVACO (Charleston, USA) has a $95 \%$ dry wt, a $19.8 \times 10^{3} M_{\mathrm{w}}$ and a $2.2 \times 10^{3} M_{\mathrm{n}} \cdot{ }^{9}$ Crude lignins were fractionated 
according to solubility by successive extractions with organic solvents as described by Mörk et al. ${ }^{10}$ for industrial birch kraft lignin. F1 (approx. 1\%) and F2 $(48.7 \%)$ were the fractions, respectively, soluble in dichloromethane and methanol. F3 (48.8\%) was the fraction insoluble in those solvents.

\subsection{Preparation of films}

Thermal moulded films were produced as follows: in order to obtain an amorphous material, starch was pre-extruded in the presence of water prior to mixing with lignin. Destructured starch and lignin powders were mixed with a Brabender mixer to give six levels of starch to lignin ratio of 100:0, 95:5, 90:10, 85:15, 80:20 and 70:30. Mixed preparations were then extruded in a Clextral BC-45 twin-screw extruder at $120^{\circ} \mathrm{C}$ in presence of water $(20-25 \% /$ dry material). No other external plasticizer was used in order to limit the number of different compounds in the system. The specific mechanical energy was about $300 \mathrm{kWh} / \mathrm{t}$. Extruded rods were moulded with a heating press $\left(140^{\circ} \mathrm{C}\right.$, $250 \mathrm{bar}, 10 \mathrm{~min}$ ) leading to $500-600 \mu \mathrm{m}$ thick films. Casting preparations were also attempted, since the amount of lignin fractions did not allow high material-consuming extrusion experiments. Films were prepared as follows: two solutions (5 $\mathrm{wt} \%$ in
$90 \%$ aqueous dimethylsulfoxide) of starch and lignin, respectively, were mixed together and stirred for approximately $12 \mathrm{~h}$ before casting onto Teflon moulds. Solutions were kept for $4-5 \mathrm{~h}$ at $80^{\circ} \mathrm{C}$ in an oven before being dried under reduced pressure at $60^{\circ} \mathrm{C}$ for $12 \mathrm{~h}$. The final film thickness was 200 $300 \mu \mathrm{m}$. The $\mathrm{F} 1$ fraction was available in too small a quantity for any film to be produced.

\subsection{Mechanical characterization}

Mechanical properties were evaluated by stressstrain tests on samples cut out of each film according to the standard ASTM D 412 method. Before testing, tensile specimens were stored for $72 \mathrm{~h}$ at two different relative humidity levels controlled by saturated salt solutions. Stress $(\sigma)$ and elongation $(\varepsilon)$ at break were measured on an INSTRON 1122 universal testing machine with a stretching speed of $0.2 \mathrm{~mm} / \mathrm{min}$. For each film, measurements were performed on at least three samples. The rather high dispersion (see error bars in Figs 2 and 3) mainly arose from the difficulty to precisely measure small deformations and from the sample thickness variations responsible for stress non-uniformity. Films containing $20 \%$ of the F3 fraction were too brittle for measurements to be performed.
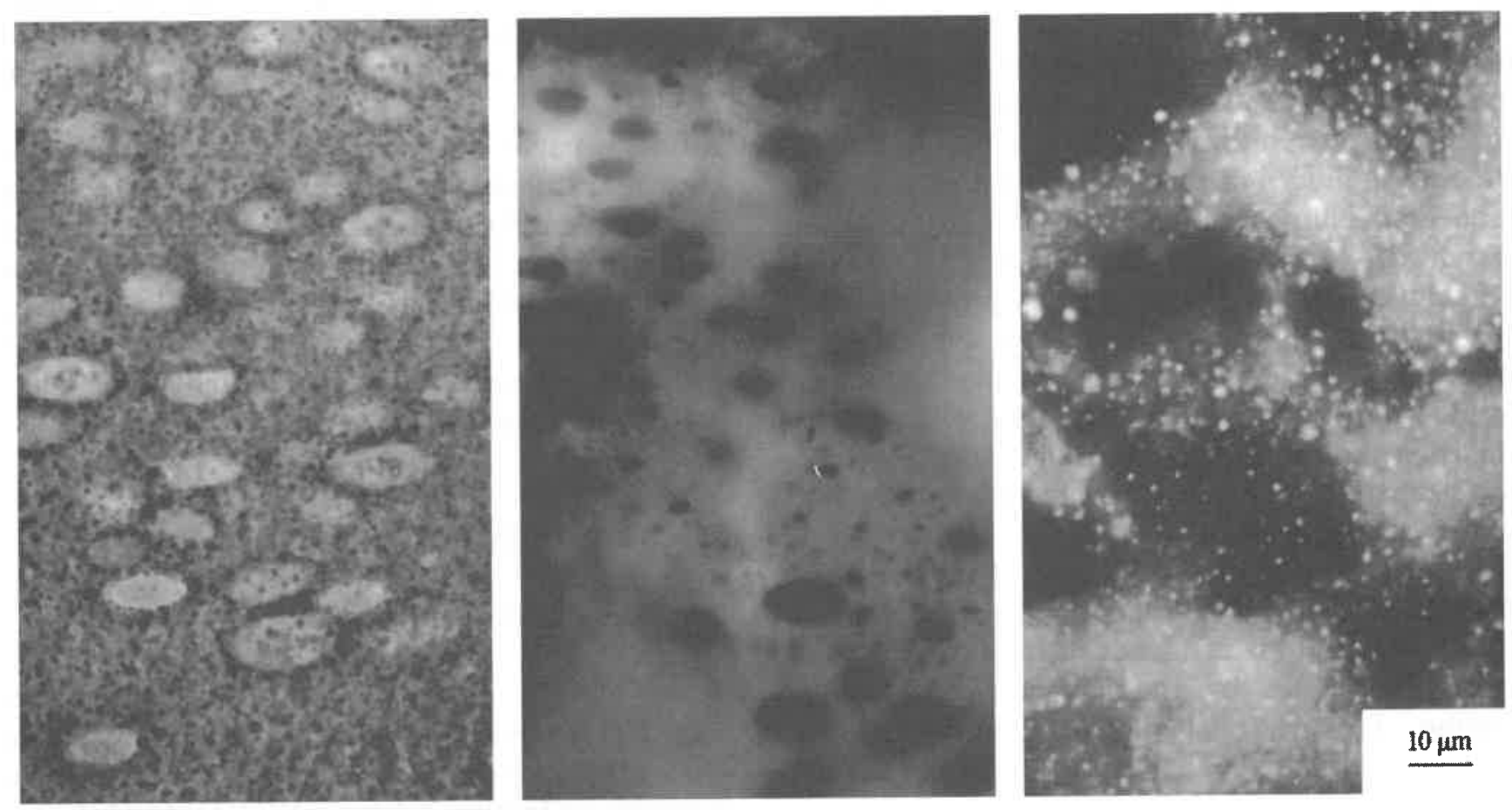

Fig. 1. Light micrographs obtained from cross-sections of a cast $80 / 20 \mathrm{starch} / \mathrm{kraft}$ lignin film with white light (left), after lugol staining (centre) and by fluorescence (right). The $10 \mu \mathrm{m}$ elliptical domains intensively stained by lugol are likely to be starch-rich domains and the fluorescent particles of a few $\mu \mathrm{m}$ dispersed lignin. 

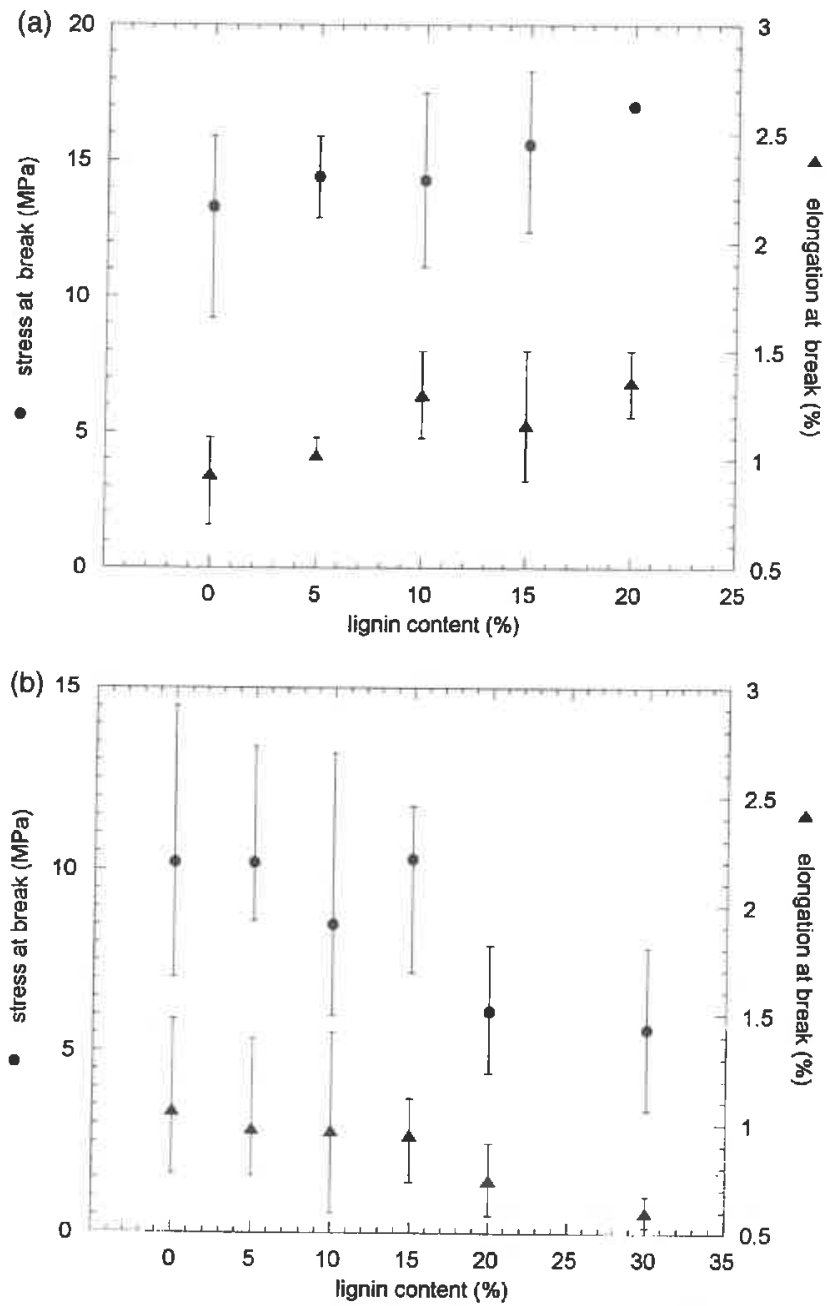

Fig. 2. Stress and elongation at break of extruded starch-kraft lignin films stored at two different humidity levels and at $25^{\circ} \mathrm{C}$ : $58 \%$ relative humidity (a) and $71 \%$ relative humidity (b). Water content: $10.6 \%(\mathrm{~A} / \mathrm{L} 100 / 0)$ to $12.6 \%(\mathrm{~A} / \mathrm{L} 70 / 30)$ at $58 \%$ relative humidity and $16(\mathrm{~A} / \mathrm{L} 100 / 0)$ to $15 \%(\mathrm{~A} / \mathrm{L} 70 / 30)$ at $71 \%$ relative humidity. Tests were performed on an INSTRON 1122 testing machine with a stretching speed of $0.2 \mathrm{~mm} / \mathrm{min}$.

\subsection{Moisture adsorption}

Constant relative humidity environments were established inside sorbostats using saturated salt solutions. Six salts among those recommended by Wolf et al. ${ }^{11}$ were used, covering a relative humidity $(\mathrm{RH})$ range from 0.33 to 0.84 . Water activity $\left(a_{\mathrm{w}}\right)$ of the films was defined as \% RH/100. Film samples were cut into small pieces and brought to zero moisture content by freeze-drying. Film moisture content was determined gravimetrically once equilibrium was reached, after 1 week. Experimental data points were fitted according to the G.A.B. (Guggenheim-Anderson-De Boer)model. ${ }^{11}$

\subsection{Water solubility}

Samples $(50-100 \mathrm{~g})$ of dry film were immersed in $40 \mathrm{ml}$ of distilled water at $25^{\circ} \mathrm{C}$ for $24 \mathrm{~h}$. Weight loss was measured gravimetrically after filtering and drying $\left(24 \mathrm{~h}\right.$ at $\left.105^{\circ} \mathrm{C}\right)$ the solid residue. Solubilized phenolic compounds were determined by measuring the absorbance of the solutions at $280 \mathrm{~nm}$ and expressed in kraft lignin equivalent. The absorption coefficient $\varepsilon$ used for the concentration calculation was $26 / \mathrm{g} / 1 / \mathrm{cm}$, as previously determined on a kraft lignin solution in $50 / 50$ aqueous dioxanne.

\subsection{Light microscopy}

Cross-sections of cast films were observed by light microscopy. The presence of starch was revealed by a specific blue staining after a 10 min treatment with lugol reagent, a diluted solution of $I_{2}$ and IK (1:2 wt:wt) in water. Lignin was detected by fluorescence using an UG5 exciter filter transmitting wavelengths from 300 to $400 \mathrm{~nm}$ and a filter barrier 41 transmitting wavelengths above $400 \mathrm{~nm}$.

\section{RESULTS AND DISCUSSION}

Translucent colourless to opaque brown films are obtained, depending on lignin concentration ranging from 0 to $30 \%$ by weight. They seem homogeneous at a macroscopic scale, but microscopic observations reveal a heterogeneous structure consisting of a starch-rich matrix and dispersed fluorescent lignin particles of about $1 \mu \mathrm{m}$ (Fig. 1). In the case of cast films, the starch matrix itself appears heterogeneous, as evidenced by lugol staining. Indeed, cast films comprised discontinuous starch domains (approx. $10 \mu \mathrm{m}$ ), whereas thermally moulded films were made of a continuous starch matrix. This difference may result from a demixion of amylose and amylopectine during the drying step of casting. This well known phenomenon is usually observed in solution before gelation. ${ }^{12}$

All the tensile specimens exhibit a nearly linear elastic deformation, consistent with the fact that no external plasticizer was added. At $58 \%$ equilibrium humidity, the elongation at break and the stress at break of starch films are, respectively, $0.93 \%$ and 13.3 $\mathrm{MPa}$ (Fig. 2(a)). The data obtained by Lourdin et al. ${ }^{1}$ for the same water content $(12.6 \%)$ are significantly higher (respectively, $3 \%$ and $35 \mathrm{MPa}$ ). This lower resistance to extension is most probably 


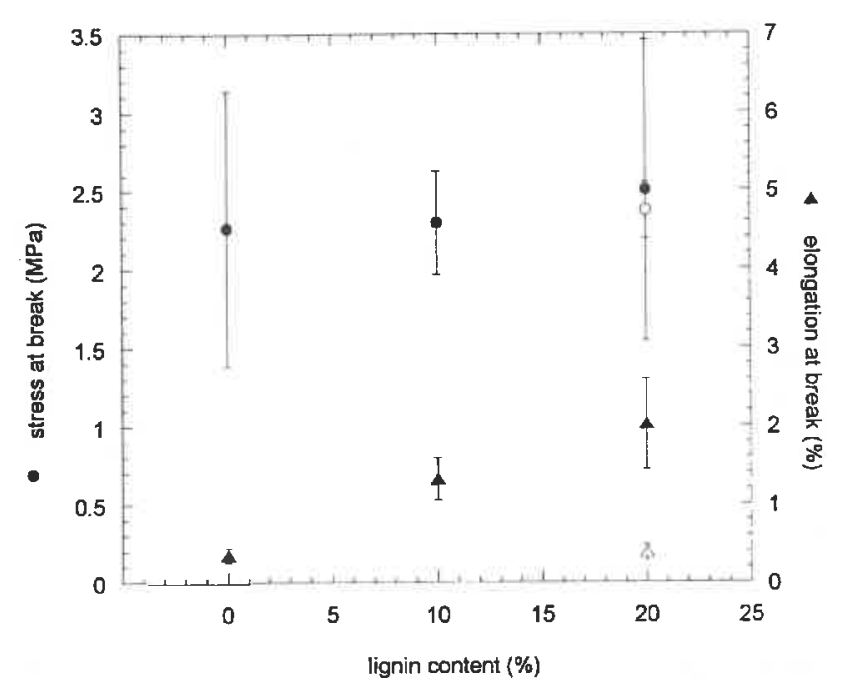

Fig. 3. Stress and elongation at break of cast films obtained from kraft lignins (filled symbols) and from the resulting F2 fraction (open symbols). Films were stored at $58 \%$ relative humidity and at $25^{\circ} \mathrm{C}$.

due to some partial depolymerization of amylose and amylopectin chains occuring during preextrusion. ${ }^{13}$ The increase in water content from $12.6 \%$ to $16 \%$ leads to a more plasticized state of pure starch: $\varepsilon$ does not change significantly, whereas $\sigma$ decreases from 13.3 MPa to 10.2 MPa (Fig. 2(b)). The plasticizing effect of water on biopolymers is well known. ${ }^{14}$ Whatever the lignin concentration, $\sigma$ and $\varepsilon$ of lignin-containing films are higher at $58 \%$ $\mathrm{RH}$ than at $71 \% \mathrm{RH}$. The incorporation of lignin leads to poorer mechanical properties at higher water content, which reflects the incompatibility between the two components. This incompatibility is not surprising, given the hydrophilic properties of starch and the relatively high hydrophobicity of lignins. It is consistent with the film heterogeneity observed in microscopy. This tendency is not observed at lower water content. This discrepancy may be explained by the fact that the incompatibility between hydrophilic starch and hydrophobic lignin is strengthened by the presence of water in the starch-rich phase.

Casting experiments performed at $58 \% \mathrm{RH}$ lead to materials with very poor mechanical resistance compared to thermally moulded films (Fig. 3). A significant increase in $\varepsilon$ was observed as a function of lignin content, whereas $\sigma$ is rather constant. This behaviour could stem from the F1 low molecular weight fraction, ${ }^{10}$ which is enriched in carboxylic and phenolic hydroxyl polar groups, as shown by their IR signals. Indeed, this fraction would thus interact with the starch matrix through hydrogen

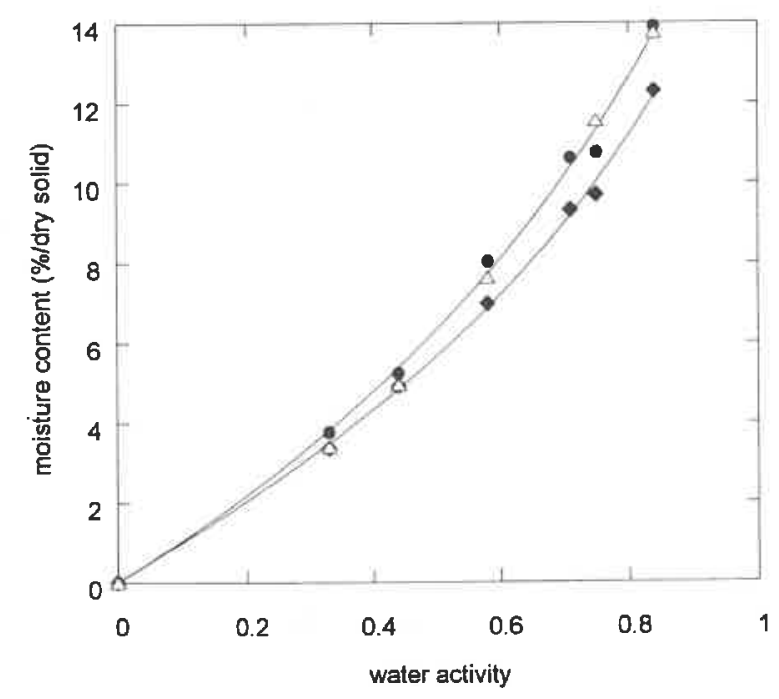

Fig. 4. Sorption isotherms $\left(25^{\circ} \mathrm{C}\right)$ of thermal moulded starchy films containing $0 \%(\odot), 15 \%(\triangle)$ and $30 \%(\diamond)$ kraft lignin.

Water activity is kept constant by saturated salt solutions.

bondings and, consequently, either improve its plasticity or increase its adherence to the lignin domains. Such a hypothesis is supported by the casting experiments with the lignin fractions: $\varepsilon$ is affected neither by $\mathrm{F} 2$ nor by $\mathrm{F} 3$ at $20 \%$ concentration. The putative effect of the $F 1$ fraction is less obvious in the case of thermal moulding, probably because the liquid state is too transient to allow molecular migration.

For the three studied films, the G.A.B. model satisfactory fits $(R>0.995)$ the sorption data points. The presence of $15 \%$ lignin does not significantly affect the sorption isotherm of starch films, whereas films containing 30\% lignin have lower equilibrium moisture contents at any $a_{\mathrm{w}}$ (Fig. 4). This observation may be attributed to the higher hydrophobicity of lignin, which nevertheless participates to water absorption. The water solubility of the thermally moulded starch film changes from 18 to $10.5 \%$ (by weight) when $30 \%$ lignin is incorporated. In this case, $7 \%$ of the dry kraft lignin is solubilized. By difference, it is estimated that $12 \%$ of dry starch is dissolved from the starch-lignin film versus $18 \%$ for the control starch film. Thus, the presence of lignin slightly improves the starch water resistance.

\section{CONCLUSIONS}

This study provided a first insight into the behaviour of kraft lignin-starch materials. 
1. Crude commercial kraft lignins could be incorporated into starch films up to a concentration of $30 \%$, with a significant decrease of extensibility at higher water content.

2. The starch/lignin materials produced both by casting and thermal moulding are composites consisting of a starch-rich matrix and dispersed lignin particles.

3. The heterogeneity of Indulin AT was confirmed. The low molecular weight lignin components are most probably responsible for a partial compatibility between starch and lignin within cast films.

4. The presence of lignin reduces the overall water affinity of thermally moulded films.

\section{ACKNOWLEDGEMENTS}

The authors would like to thank Dr Gerald Katz from the WESTVACO Society (Charleston, USA) for providing the lignin sample and technical informations. Brigitte Vian and Danièle Reis (Laboratoire de Pathologie Végétale, INA-PG, Paris) are gratefully acknowledged for their help concerning microscopic observations. Eugène Drouet (INRA, Nantes) is also acknowledged for extrusion performing.

\section{REFERENCES}

1. Lourdin, D., Colonna, P. and Della Valle, G., in Gueguen, J. (Ed.), Valorisations non-alimentaires des grandes productions agricoles, Les Colloques INRA, Vol. 71, INRA, Paris, France, 1995, pp. 241-248.

2. Sagar, A. and Merrill, E., J. Appl. Polym. Sci., 1995, 58, 1647-1656.

3. Kosikowa, B., Demianova, V. and Kacurakova, M., J. Appl. Polym. Sci., 1993, 47, 1065-1073.

4. Oliveira, W. and Glasser, W. G., J. Wood Chem. Techn., 1994, 14(1), 119-126.

5. Rials, T. G. and Glasser, W. G., J. Appl. Polym. Sci., $1989,37,2399-2415$.

6. Muzzarelli, R. and Ilari, P., Carbohydr. Polym., 1994, 23, $155-160$

7. Baumberger, S., Lapierre, C., Monties, B., Lourdin, D. and Colonna, P., Indust. Crops Prod., 1997, 6, 253-258.

8. Marton, J., in Lignins, Sarkenen, K. V. and Ludwig, C. H. (Eds.), Wiley Interscience, New York, USA, 1971, pp. 639-695.

9. Glasser, W., Davé, V. and Frazier, E., J. Wood Chem. Techn., 1993, 13(4), 545-559.

10. Mörk, R., Yoshida, H. and Kringstad, P., Holzforshung, 1986, 40, 51-60.

11. Wolf, W., Spiess, G. and Jung, G., J. Food Engng, 1984, 3, 51-53.

12. Leloup, V., Colonna, P. and Buléon, A., J. Cereal Sci., 1991, 13, 1-13.

13. Colonna, P. and Buléon, A., in Colonna, P. and Della Valle, G. (Eds.), La cuisson-extrusion, Lavoisier Technique et Documentation, Paris, France, 1995, 19 pp.

14. Slade, L. and Levine, H., J. Food Engng, 1995, 24, 431509. 
